\title{
O sentido da maternidade e da infertilidade: um discurso singular
}

\author{
The meaning of maternity and infertility: \\ A singular speech
}

\author{
Patrícia Gomes Accioly LINS ${ }^{1}$ \\ Elci Antonia de Macedo Ribeiro PATTI ${ }^{2}$ \\ Antonio Cézar PERON ${ }^{3}$ \\ Valéria BARBIERI ${ }^{4}$
}

\section{Resumo}

A infertilidade é definida como ausência da concepção após 12 meses de atividade sexual sem uso de contraceptivos. Sua prevalência na população varia entre os diferentes países: entre um mínimo de $5 \%$ e um máximo de $30 \%$ de todos os casais. As técnicas empregadas para o tratamento da infertilidade são conhecidas como "reprodução assistida". A realização do presente trabalho teve como objetivo principal investigar, nas mulheres entrevistadas, os aspectos inconscientes do desejo singular pela maternidade e a dificuldade do feminino em lidar com a impossibilidade de gerar um filho. A amostra foi composta por 200 mulheres que estavam sendo submetidas a tratamentos de reprodução humana assistida. Foram realizadas quatro entrevistas com cada participante, e os aspectos inconscientes foram analisados a partir de cada um dos discursos, que foram analisados e interpretados numa visão biopsicossocial, com ênfase, entretanto, no pensamento psicanalítico. A análise dos discursos foi realizada através da confrontação dos dados e supostos teóricos; a pesquisa segue, dessa maneira, uma metodologia quali-quantitativa.

Palavras-chave: Gravidez; Infertilidade; Instinto; Relação mãe-criança; Técnicas reprodutivas.

\begin{abstract}
In the literature infertility is defined as the absence of conception after 12 months of sexual activity without contraceptive use. Its prevalence in the population varies among different countries, from a minimum of $5 \%$ to a maximum of $30 \%$ of all couples. Considering the physical and psychic suffering of women who undergo reproduction treatments, the main aim of this study was to investigate the unconscious aspects of the singular desire for maternity and the difficulty

$\boldsymbol{\nabla v} \mathbf{v}$

1 Psicóloga. Ribeirão Preto, SP, Brasil.

2 Universidade de Franca, Ciências Biológicas e da Saúde, Grupo de Pesquisa em Psicanálise. Av. Dr. Armando Salles Oliveira, 201, Pq. Universitário, 14404-600, Franca, SP, Brasil. Correspondência para/Correspondence to: E.A.M.R. PATTI. E-mail: <elcipatti@hotmail.com>

${ }^{3}$ Universidade de Franca, Ciências Biológicas e da Saúde, Curso de Especialização em Psicanálise. Franca, SP, Brasil.

${ }^{4}$ Universidade de São Paulo, Faculdade de Filosofia, Ciências e Letras de Ribeirão Preto, Departamento de Psicologia. Ribeirão Preto, SP, Brasil.

Agradecimentos: Aos pacientes do Centro de Reprodução Humana Prof. Franco Júnior de Ribeirão Preto, onde os dados foram coletados
\end{abstract}


in coping with the impossibility of creating a child. There was a subversion of the body, where "Another" body appears in enigmatic form in their statements. It is here that the desire is installed. Individual interviews were carried out, from which the manifest unconscious aspects contained within the statements of these women were studied and analyzed from a biopsychosocial perspective, attributing greater relevance to the contributions of psychoanalysis.

Keywords: Pregnancy; Infertility; Instinct; Mother-child relations; Reproductive techniques.

A reprodução, conforme Ferreira (1986), é o processo biológico que permite aos seres vivos a perpetuação da espécie. Para os seres humanos, ela sempre foi muito importante e muitas vezes considerada como benção. Nas escrituras da Bíblia sagrada, encontra-se em Gn. 1:28 (Nova Edição Papal) "Então Deus os abençoou e Ihes disse: frutificai-a e multiplicai-vos; enchei a terra e sujeitai-a; dominai sobre os peixes do mar, sobre as aves do céu e sobre os animais que arrastam sobre a terra". Em SI. 127:3, o filho é representado como benção divina; "Eis que os filhos são herança da parte do Senhor, e o fruto do ventre o seu galardão". Nos humanos, o processo reprodutivo é psicossexual. Porém, para que de fato possam reproduzir-se, é preciso que homens e mulheres sejam férteis. Maldonado $(1987$, p.15) reflete que "...desde muitos séculos, a fecundidade é tida como uma benção divina, ao passo que a infertilidade é tida como um castigo". Para alguns homens e mulheres, o conhecimento de seu próprio poder reprodutivo é elemento básico de autoestima.

A geração de descendentes não se limita a uma questão biológica relativa à sobrevivência da espécie, mas comporta também uma dimensão psíquica, emocional e sociocultural (Faria, 2001), sendo bastante rica em conteúdos simbólicos. Nesse sentido, a infertilidade do casal, independentemente de sua causa, é sempre motivo de grande sofrimento, colocando o casal num plano de especial fragilidade (Romeu, 2000).

Segundo Vayena, Rowe e Griffin (2001), a infertilidade é definida como a ausência da concepção após 12 meses de atividade sexual sem uso de contraceptivos. no mundo todo, cerca de 80 milhões de pessoas sofrem com esse problema. Sua prevalência na população varia entre os diferentes países: de um mínimo de 5\% a um máximo de 30\% de todos os casais. Desses, aproximadamente 10\% não resolvem o problema espontaneamente, e muitos buscam ajuda médica, quando eventualmente são oferecidas Técnicas de Reprodução Assistida (TRA). Obrigatoriamente, o tratamento de um casal deverá ser realizado após uma investigação detalhada das possíveis causas da infertilidade, para se determinar o melhor tratamento. Entretanto, diversos fatores - faixa etária, hábitos, meio ambiente e fatores psicológicos -, podem influenciar o sucesso do tratamento (Franco Jr., 1997).

A psicanálise concebe a maternidade como expressão do feminino: observando as reações infantis à percepção das diferenças anatômicas entre os sexos, Freud (1905-1925/1990) articula noções centrais na psicanálise, como a força fálica, a castração e a inveja do pênis. A constituição egóica, a orientação sexual, as patologias e as inibições podem ser entendidas como efeitos dos conflitos suscitados pela constatação das diferenças anatômicas, assim como os desejos incestuosos, cuja compreensão teórica se organiza através do Complexo de Édipo.

Desde suas primeiras investigações sobre a sexualidade, a psicanálise direcionou-se a desvincular o desejo sexual de uma aspiração à descendência, como Freud relata em seu texto, sobre o Narcisismo (Freud, 1914/1996, p.85), "o indivíduo leva realmente uma existência dúplice: uma para servir as suas próprias finalidades e outra como elo numa corrente. Como veículo mortal de uma substância (possivelmente imortal), como apêndice de seu germoplasma, ele põe suas energias à disposição (da preservação da espécie) em troca de uma retribuição de prazer". A sexualidade humana, infantil ou adulta, busca satisfação, enquanto o propósito de ter filhos coloca-se do lado das pulsões de autoconservação, a serviço de aspirações egoico-narcísicas. Portanto, a experiência da infertilidade 
pode promover um abalo na estrutura narcísica do sujeito, pois o projeto de imortalidade do eu e do casal encontra-se ameaçado, abalando os referenciais narcísicos de cada sujeito.

Na literatura, os trabalhos sobre os aspectos psicológicos da infertilidade apresentam-se basicamente em duas vertentes: a primeira refere-se a complexos e dificuldades emocionais envolvidos na etiologia da infertilidade, e a outra diz respeito às consequências que a infertilidade acarretaria na vida do sujeito e, consequentemente, do casal.

Quanto aos efeitos psicológicos da infertilidade na vida das pessoas, Lopes, Melamed e Martucci (2003) referem uma progressão de reações psicológicas nos pacientes inférteis, que se inicia com a negação e termina com a aceitação, passando pelo isolamento, busca da culpa e depressão. O percurso emocional geralmente inicia-se com o trajeto percorrido pelo casal em busca da resolução do seu problema, que, geralmente, é longa e, às vezes, dolorosa. Oddens, Tonkelaar e Nieuwenhuyse (1999) afirmaram que um em cada quatro pacientes inférteis apresentava sinais de depressão.

De fato, a infertilidade provoca uma crise na vida do casal, que requer uma redefinição de suas identidades pessoais e conjugais, sendo uma de suas consequências a depressão pela perda do corpo saudável e o receio do rompimento do seu relacionamento.

A crise da infertilidade pode iniciar-se durante o processo de investigação e/ou no próprio tratamento, pois ambos são períodos de grande desgaste emocional que interferem na sexualidade do casal. O desajuste emocional pode surgir a partir do longo diagnóstico (Lee, Sun, \& Chao, 2001), de tentativas malsucedidas de conceber e dos procedimentos terapêuticos requeridos (Hammarberg, Astbury, \& Baker, 2001).

Diante disso, a realização do presente trabalho teve como objetivo principal investigar, nas mulheres entrevistadas, os aspectos inconscientes do desejo singular pela maternidade e a dificuldade do feminino em lidar com a impossibilidade de gerar um filho.

\section{Método}

O universo da pesquisa foi constituído por 200 mulheres em tratamento de reprodução assistida com indicação específica para Fertilização In Vitro (FIV) e Intra Cytoplasmic Sperm Injection (ICSI). As condições socioeconômicas foram ím-pares, com diferentes níveis de escolaridade; a média de idade foi de 33,4 4 4,9 anos, com variação de 18 a 43 anos. Sobre as pacientes, foram anotadas informações gerais relacionadas à idade e à história da infertilidade. Essas mulheres apresentaram diferentes diagnósticos de infertilidade; a causa foi masculina em $46 \%$ dos casos, (92/200), feminina em $25 \%$ (50/200) e referente a ambos em 29\% (58/200). A infertilidade foi primária em 79\% (158/200) e secundária em 21\% (42/200).

Como instrumento de coleta de dados, foi utilizado o método clínico psicanalítico das entrevistas preliminares. Trata-se de um tempo de trabalho prévio, realizado em quatro entrevistas divididas em dois tempos, um de compreender e outro de concluir, nesse momento o terapeuta toma a decisão. O método segue as regras da psicanálise e utiliza o método descrito por Freud como tratamento de ensaio e adaptado por Lacan (Quinet, 1999). As entrevistas foram utilizadas com o propósito de averiguar qual era o sentido da demanda, que foi analisada durante as quatro entrevistas num tempo prévio de avaliação e diagnóstico potencial realizado antes de iniciar o tratamento de reprodução humana.

Os dados foram analisados por meio dos discursos obtidos nas entrevistas. Os discursos foram tomados como unidade de análise, complexa de significação, e anotados durante as entrevistas. Partindo-se do princípio de que o sujeito inconsciente é representado pelo sintoma, o sintoma foi questionado e analisado na tentativa de compreender questões singulares.

O trabalho foi submetido ao Comissão Nacional de Ética em Pesquisa (CONEP).

\section{Resultados}

As principais informações foram colhidas durante os atendimentos clínicos realizados nas 
quatro entrevistas. Os discursos das participantes foram transcritos na íntegra, analisados e confrontados com os dados e supostos teóricos. Os resultados indicaram que a infertilidade foi vivida com muito sofrimento e, em muitos casos, foi vivenciada como doença. Os sentimentos comuns foram de impotência, culpa e sensação de vazio. A experiência da infertilidade foi vivenciada pela formação de vários sintomas, pois atinge a vida das mulheres nos aspectos físicos, psíquicos, sociais e econômicos. O estudo apontou diferenças muito importantes entre desejar ser mãe e querer ter um filho em reprodução humana assistida. A seguir, serão apresentados fragmentos dos discursos, que sintetizam a presença dos sintomas e dos prejuízos advindos da infertilidade na vida dessas mulheres.

\section{Discussão}

Através da análise dos discursos, serão apresentadas articulações com a teoria psicanalítica. Volnovich (1991, p.76), relembrando a obra de Freud, relata que "os sintomas são definidos por ele como manifestações do recalcado. A cura psicanalítica consiste em articular o sintoma com o desejo recalcado, o que é denominado desvendar o sentido, articulação da qual é possível assumir a própria história". Assumindo a própria história, o ser humano consegue criar novos sentidos para a própria vida.

Pacientes de reprodução humana assistida geralmente apresentam grande dificuldade em assumir a própria história, pois desvendar o sentido é muitas vezes doloroso, ameaçador e angustiante. Ainda que, na maioria das vezes, o filho venha para preencher uma falta, não seria apenas o vazio produzido pela castração que impulsionaria uma mulher a desejar ter um filho e a tê-lo; há outros vazios marcados por perdas ao longo de sua vida, tais como abortos (espontâneos e provocados), morte de filho (intrauterino, recém-nascido, criança), perdas orgânicas (a não fertilidade dos ovários) entre outros. Dependendo dessa falta, esse filho poderia vir embalado por projeções e idealizações para compensar uma solidão, pela ilusão de salvar um casamento ou como garantia de estabilidade 390 financeira, entre outros.
Através de alguns recortes dos discursos das entrevistadas, aparecerá de uma forma singular a significação da infertilidade para cada uma:
S - 37 anos, área de atuação jurídica: tudo na minha vida saiu como eu sempre quis, programei tudo, desde formatura, casa- mento, gravidez, escolhi o J. não para ser meu marido, mas sim para ser o pai dos meus filhos, porque eu sabia que ele seria um bom pai, é muito parecido com o meu. Eu não consigo ser mãe, reproduzir, será que Deus esqueceu de mim? Eu só quero ter um filho, saber o que é ser mulher. Meu casa- mento está acabando, não tenho mais desejo sexual. Afinal, eu sirvo para quê?.

Nesse trecho de discurso, aparece um desejo de ter um filho associado à busca de uma identificação feminina do ser mulher pela via da maternidade, "eu só quero ter um filho, saber o que é ser mulher". Esse discurso nos remete aos estudos de Freud, especificamente aos textos sobre a "Sexualidade feminina" (Freud, 1931/1990), "Feminilidade" (Freud, 1932/1990), em que a maternidade viabilizaria a abertura do caminho à feminilidade. Entretanto, algo impede a realização desse desejo, o sujeito fica infértil, o equívoco fica escancarado, não é possivel ser mulher por essa via.

$$
\begin{aligned}
& \text { L - } 36 \text { anos, área de atuação saúde: não sei } \\
& \text { o que é relação sexual há quatro meses, } \\
& \text { desde a minha última tentativa. Os } \\
& \text { medicamentos me deixaram dolorida, } \\
& \text { inchada, deprimi com o resultado negativo, } \\
& \text { me revoltei e até me afastei do meu marido. } \\
& \text { Já tenho uma filha de tratamento, ela } \\
& \text { sempre pede um irmão, quer saber por que } \\
& \text { ele não vem, não sei o que falar, me sinto } \\
& \text { impotente, dá medo, uma sensação de } \\
& \text { fracasso. Ela está percebendo que sou } \\
& \text { incompetente. } \\
& \text { M- } 34 \text { anos, área de atuação saúde: tenho } \\
& \text { medo, muito medo de engravidar, e se Deus } \\
& \text { me der e depois me tirar ou me der uma } \\
& \text { criança deficiente como castigo? Desde } \\
& \text { quando fiz um aborto, ainda não passei } \\
& \text { nada de ruim, não paguei pelo meu pecado. } \\
& \text { Acho melhor não engravidar. }
\end{aligned}
$$

Esses dois recortes do discurso sobre a questão do engravidar ou não engravidar apresentam 
uma relação com a impotência e com o castigo e deixam clara a confusão de cada uma sobre o lugar que esse filho iria ocupar em suas vidas. Para uma, está relacionado a agradar a filha, e, para outra, a criança pode vir com defeito para castigá-la. Nas duas narrativas está presentificado um gozo sadomasoquista. A maternidade é algo que traz sofrimento para essas duas mulheres.

S - 32 anos, área de atuação indústria: eu perdi meus gêmeos depois do parto, foi na primeira tentativa que eu consegui engravidar, depois engravidei espontaneamente de (L), ai fiz outra tentativa de tratamento e veio só um, o $(A)$. Estou aqui novamente porque quero engravidar de gêmeos, eu não consigo aceitar que os meus morreram.

Nesse discurso, o sujeito traz um desejo de ter um filho para tamponar uma falta; existe uma não aceitação diante da perda de seus filhos gêmeos, a angústia de castração é atualizada e funciona na neurose como permanência do desejo recalcado, representado aqui pela não aceitação da falta dos filhos. Para Freud (1926/1990), a relação do sujeito com a castração surge como angústia e constitui-se em sintoma, sendo pautada na existência de uma equivalência da criança com o falo, o falo como forma de disfarçar a castração. Para Lacan (1969/2003), a criança pode ser representada como um objeto tampão da falta. Ao se negar a castração, busca-se algo para tamponá-la - nesse caso, o filho -, impossibilitando assim o encontro com seu verdadeiro desejo inconsciente.

Devido à limitação da pesquisa, apenas alguns discursos foram apresentados para análise como síntese do trabalho.

Conforme constatado nos discursos deste estudo, aparece um feminino em estado de uma intensa angústia diante da infertilidade, o que remete o sujeito à sua angústia de castração, com cada um expressando esse mal-estar de forma muito peculiar. O conflito entre desejar e querer fica claro, sem haver uma conciliação: o sintoma da infertilidade é o denunciador de que tem um desejo inconsciente que é proibido de ser revelado, e que não faz parceria com o querer de cada uma delas.

"O processo de castração pode ser vivido imaginariamente como uma ameaça, um castigo, mas jamais como um fato isolado, pois se constitui como um complexo que coloca em ação um feixe de relações..." (Silva, 1995, p.139). Desse modo, ocorre uma subversão do corpo orgânico, cujo "outro" corpo aparece de forma enigmática em seu discurso.

Outros sintomas aparecem como reveladores de que existe ali um desejo para ser falado e elaborado; o sujeito está impedido de apresentar seu desejo, e a única saída são os sintomas: funções sexuais alteradas, inibições, medos, dores, tristeza, depressão entre outros. De acordo com Lacan (1985), Freud descobriu o inconsciente e situou o sintoma como algo denunciador da verdade do sujeito.

Como nenhuma pesquisa é perfeita, esta também teve suas limitações. Os dados foram colhidos durante dois anos de trabalho dentro de um Centro de Reprodução Humana Assistida; talvez devido ao fato de o atendimento psicológico ser oferecido na clínica como parte do tratamento, muitas pacientes optavam em não realizar as entrevistas com a psicóloga, manifestando assim uma forma de resistência consciente ou inconsciente. Porém, todas as pacientes que optaram em participar da pesquisa assinaram o termo de consentimento livre e esclarecido e mostraram-se colaboradoras e motivadas durante os atendimentos.

Por meio da articulação entre os estudos psicanalíticos e os discursos dos sujeitos entrevistados, foi falado da grande dificuldade em lidar com a falta, cada uma com suas peculiaridades.

A infertilidade é um sintoma que provoca uma reabertura da ferida narcísica, alterando assim as funções vitais do sujeito, produzindo uma variedade de sintomas e muitas vezes prejudicando relacionamentos sexuais, conjugais, sociais, profissionais e familiares. Portanto, a infertilidade aparece como uma falta insuportável; como vimos nos recortes de seus discursos, a grande maioria das participantes fala de suas experiências com um grande mal-estar, aquilatando prejuízos de ordem biopsicossocial.

As participantes deste estudo, apresentando uma diversidade de sintomas, demonstraram dificuldades em simbolizar esses sofrimentos marcados no corpo de cada uma. 
Como esclarece Patti (2004), em sua pesquisa sobre a mulher, que, quando o sujeito se reconhece faltoso e não defeituoso, pode falar sobre isso para um profissional com uma escuta psicanalítica, abrindo assim, um campo para simbolização, e podendo dar uma nova significação para aquilo que até então trazia grandes sofrimentos marcados corporalmente. "A mulher, quando consegue reconhecer seus atributos (o buraco, o vazio, a abertura, enfim essa suposta falta), que caracterizam o potencial de receptividade feminina, fica livre desse fantasma sadomasoquista e pode ser uma mulher com toda sua potencialidade" (p.83).

O trabalho psicanalítico junto com uma equipe multidisciplinar pode trazer benefícios para evitar vários tipos de sofrimentos que trazem grandes danos ao ser humano. O sujeito sofredor, ao falar para um profissional com uma escuta psicanalítica, pode representar através de palavras e atos seu desejo inconsciente singular, abrindo assim um espaço para novas significações, e podendo mudar de posição em relação aquilo que traz dores, angústias e sofrimentos variados, e reinventar novas formas de viver.

O compromisso da psicanálise é tratar dos pontos de impasse e mal-estar: é fazer valer o impossível como causa do desejo.

\section{Referências}

Faria, C. (2001). Aspectos psicológicos da infertilidade. In M. C. Canavarro (Ed.), Psicologia da gravidez e maternidade (pp.189-209). Coimbra: Quarteto.

Ferreira, A. B. H. (1986). Novo Dicionário Aurélio da Língua Portuguesa ( $2^{a}$ ed.) Rio de Janeiro: Nova Fronteira.

Franco, J. G., Jr., (1997). Reprodução assistida. Rio de Janeiro: Revinter.

Freud, S. (1990). Algumas conseqüências psíquicas da distinção anatômica entre os sexos. In S. Freud. Edição standard brasileira das obras psicológicas completas de Sigmund Freud (Vol. 19). Rio de Janeiro: Imago. (Originalmente publicado em 1905-1925).

Freud, S. (1990). Feminilidade. In S. Freud. Edição standard brasileira das obras psicológicas completas de Sigmund Freud (Vol. 22, pp.139-165). Rio de Janeiro: Imago. (Originalmente publicado em 1932).

Freud, S. (1990). Inibições, sintomas e ansiedade. In S. Freud. Edição standard brasileira das obras psicológicas completas de Sigmund Freud (Vol. 20). Rio de Janeiro: Imago. (Originalmente publicado em 1926).
Freud, S. (1990). Sexualidade Feminina. In S. Freud. Edição standard brasileira das obras psicológicas completas de Sigmund Freud (Vol. 21). Rio de Janeiro: Imago. (Originalmente publicado em 1931).

Freud, S. (1990). Três ensaios sobre a teoria da sexualidade. In S. Freud. Edição standard brasileira das obras psicológicas completas de Sigmund Freud (Vol. 7, pp.119-129). Rio de Janeiro: Imago. (Originalmente publicado em 1905).

Freud, S.(1996). Sobre o narcisismo: uma introdução. In S. Freud. Edição standard brasileira das obras psicológicas completas de Sigmund Freud (Vol. 14, pp.75-108). Rio de Janeiro: Imago. (Originalmente publicado em 1914).

Hammarberg, K., Astbury, J., \& Baker, H. W. G. (2001). Women's experience of IVF: A follow-up study. Human Reproduction, 16(1), 374-383.

Lacan, J. (1985). O seminário: livro 20 mais, ainda (2a ed.). Rio de Janeiro: Jorge Zahar Editor.

Lacan, J. (2003). Nota sobre a criança. In J. Lacan. Outros escritos. (pp.369-370). Rio de Janeiro: Jorge Zahar Editor. (Originalmente publicado em 1969).

Lee, T. Y., Sun, G. H., \& Chao, S.C. (2001). The effect of on infertility diagnosis on the distress, marital and sexual satisfaction between husbands and wives in Taiwan. Human Reproduction, 16(1), 762-776.

Lopes, G., Melamed, R. M. M., \& Martucci, R. C. (2003). Aspectos emocionais da infertilidade. In E. R. Wroclawski, \& E. Borges Jr. (Orgs.), II Consenso Brasileiro de Infertilidade Masculina. São Paulo: Sociedade Brasileira de Urologia.

Maldonado, M. T. P. (1987). Psicologia da gravidez (9a ed.). Petrópolis: Vozes.

Oddens, B. J., Tonkelaar, I., \& Nieuwenhuyse, H. (1999). Psychosocial experiences in women facing fertility problems: A comparative survey. Human Reproduction, 14(1), 255-261.

Patti, E. A. M. R. (2004). O que pode uma mulher? Sexualidade, educação e trabalho. Franca: Unesp.

Quinet, A. (1999). As 4+1 condições da análise (4ª ed.). Rio de Janeiro: Jorge Zahar Editor.

Romeu, L. C. (2000). Avaliação da personalidade de mulheres inférteis: uma contribuição do Rorschach temático (Dissertação de mestrado não-publicada). Universidade de São Paulo, Ribeirão Preto.

Silva, M. E. A. (1995). O gozo feminino. São Paulo: lluminaras.

Vayena, E., Rowe, P.J., \& Griffin, P. D. (Eds.). (2001, September). Current practices and controversies in assisted reproduction: report of a WHO meeting on medical, ethical and social aspects of assisted reproduction. Geneva: WHO.

Volnovich, J. (1991). Lições introdutórias à psicanálise de crianças. Rio de Janeiro: Relume-Dumará.

Recebido em: 2/5/2012

Aprovado em: 22/5/2012 